\title{
Profil Kepribadian Gamers Esports DotA 2 di Kota Bandung
}

\author{
Aryo Triutama*, Milda Yanuvianti \\ Prodi Psikologi, Fakultas Psikologi, Universitas Islam Bandung, Indonesia. \\ *Aryotriutama@gmail.com, milda.yanuvianti@unisba.ac.id
}

\begin{abstract}
Currently online games have become one of the branches of sports known as Esports. In the competition of Esports, DotA 2 became game the most profitablein terms of prizes. 2018 became the best year in DotA 2 Esports Indonesia, but the development of Esports Dota 2 in Indonesia has decreased in 2019. Despite having problems, the DotA 2 game is still popular in several internet cafes in the city of Bandung. According to Collins, Freeman, \& Chamarro-Premuzic (2012) personality traits related to the behavior of playing online games. As the development of knowledge, personality traits can be measured through the concept of Big Five Personality Traits, according to Strus, Cieciuch, \& Rowiński (2014) In big five personality traits there are 5 dimensions, namely Emotional Stability vs. Neurotism, Extraversion, Agreeableness, Conscientiousness, and Openness / Intellect. In this study, the method used is descriptive with a purposive sampling technique of 34 Esports gamers in the city of Bandung. The purpose of this study was to determine the personality profile of Esports gamers in the city of Bandng. Researchers used the IPIP BFM-25 standard measuring instrument made by Akhtar \& Azwar, (2018). The results of this study show the dimensions of Conscientiousness (82.4\%), Agreeableness (88.2\%), and Intellect (91.2\%) became dominant in the score with a high category, and Emotional Stability $(64.7 \%)$ become the dominant dimension in the low score category.
\end{abstract}

Keywords: Personality Traits, Big Five Personality Traits, Gamers Esports, DotA 2.

\begin{abstract}
Abstrak. Saat ini game online sudah menjadi salah satu cabang olahraga yang dikenal dengan Esports. Dalam kompetisi Esports, DotA 2 menjadi game yang paling profit dari segi hadiah. Tahun 2018 menjadi tahun terbaik di Esports DotA 2 Indonesia, namun perkembagan Esports Dota 2 di Indonesia mengalami penurunan pada tahun 2019. Meskipun memiliki permasalahan namun game DotA 2 masih menjadi populer di beberapa warnet di kota Bandung. Menurut Collins, Freeman, \& ChamarroPremuzic (2012) personality traits terkait dengan perilaku bermain game online. Seiring perkembangan ilmunya, personality traits dapat diukur melalui konsep Big Five Personality Traits, menurut Strus, Cieciuch, \& Rowiński (2014) Dalam big five personality traits terdapat 5 dimensi, yaitu Emotional Stability vs Neurotism, Extraversion, Agreeableness, Conscientiousness, dan openness / Intellect. Dalam penelitian ini, metode yang dipakai adalah deskriptif dengan teknik sampling purposive terhadap 34 gamers Esports di kota Bandung. Tujuan dari penelitian ini untuk mengetahui profil kepribadian gamers Esports di kota Bandng. Peneliti menggunakan alat ukur baku IPIP BFM-25 yang dibuat oleh Akhtar \& Azwar, (2018). Hasil dari penelitian ini menunjukan dimensi Conscientiousness (82,4\%), Agreeableness $(88,2 \%)$, dan Intellect $(91,2 \%)$ menjadi dominan pada skor dengan kategori tinggi, dan Emotional Stability $(64,7 \%)$ menjadi dimensi yang dominan pada kategori skor rendah.
\end{abstract}

Kata Kunci: Personality Traits, Big Five Personality Traits, Gamers Esports, DotA 2. 


\section{A. Pendahuluan}

Kepopuleran game online di dunia sendiri semakin menjadi suatu industri hiburan yang cukup diperhitungkan, dilansir dari NewZoo (2019) game online menghasilkan pendapatan global sebesar US\$137.9 Milyar. Saat ini game online sudah menjadi salah satu cabang olahraga yang disebut Esports. Dari berbagai cabang game online yang dipertandingkan di Esports, DotA 2 merupakan salah satu game online yang dipertandingkan. DotA 2 secara global merupakan game yang paling profit secara hadiah dari kompetisinya.

Pada tahun 2018 DotA 2 menjadi game online yang berkembang pesat di Indonesia a Indonesia baik dari segi pemain dan prestasi sangat berkembang pesat pada tahun tersebut. Hal itu dilihat dari hampir setiap kualifikasi terbuka dan tertutup selalu ada tim Indonesia yang mengisi slot atau kursi untuk bermain pada suatu kompetisi berskala internasional (RevivalTV, 2018). Namun pada tahun 2019 keadaannya berubah, organisasi atau tim besar di Indonesia yang bergerak di bidang Esports seperti tim Rex Regum Qeon (RRQ) malah membubarkan tim Esports DotA 2 nya pada tanggal 25 April 2019, lalu The Prime Esports pada 29 April, (Hybrid, 2019) dan Evos Esports pada 10 Oktober 2019 (GridGames, 2019). Dilansir dari laman revival.tv pada tahun 2018 hanya ada dua pemain pro di Indonesia yang pernah menjadi bagian dari suatu tim di luar Indonesia hingga saat ini dan mereka bisa menjuarai suatu kompetisi internasional yang jika dibandingkan dengan jumlah pemain pro Indonesia lainnya yang jumlahnya mencapai sekitar 20 orang (RevivalTV, 2018). Meskipun sampai saat ini DotA 2 masih mengalami permasalahan dalam pengembangan game nya di Indonesia, namun game DotA 2 masih menjadi game populer di 10 warnet terkenal dan 5 warnet terpencil di kota Bandung

Dalam bermain game online khususnya DotA 2 yang dimainkan secara berkelompok, sudah sewajarnya terdapat berbagai macam pendapat, perilaku, sikap dan lainnya dari tiap anggota dalam upaya suatu tim untuk mengejar tujuannya, hal tersebut sejalan dengan penelitian Collins, Freeman, \& Chamarro-Premuzic (2012) yang berpendapat bahwa personality traits terkait dengan perilaku bermain game online. Menurut Costa \& McCrae (2006) Trait Dapat dengan baik untuk memprediksi tingkah laku untuk jarak waktu yang panjang. Untuk menggambarkan traits seseorang dapat menggunakan konsep big five personality traits.

Menurut Strus, Cieciuch, \& Rowiński (2014) Dalam big five personality traits terdapat 5 dimensi yang masing masing berdiri sendiri, yaitu Emotional Stability vs Neurotism, Extraversion, Agreeableness, Conscientiousness, dan openness / Intellect. Berdasarkan penelitian di China oleh Teng (2008) telah dilakukan suatu studi mengenai big five personality traits terhadap pelajar yang bermain game terdapat data bahwa para gamers memiliki skor yang tinggi pada dimensi openness, conscientiousness, dan extravertion (Teng, 2008). Selain itu, penelitian Rachma \& Handoyo (2016) yang menyebutkan dimensi Conscientiousness, Emotional Stability, dan Openness berpengaruh signifikan terhadap expatriate leader (konteks yang dimaksud pekerjaan).

Berdasarkan latar belakang yang telah diuraikan, maka perumusan masalah dalam penelitian ini sebagai berikut: "bagaimana gambaran personality traits pada pemain Dota 2 di Kota Bandung Bandung ?”. Selanjutnya, maksud dalam penelitian ini untuk mendapatkan data empirik mengenai Personality Traits pada gamers Esports DotA 2 di kota Bandung, serta tujuannya untuk memperoleh gambaran data empirik Personality Traits pada gamers Esports DotA 2 di kota Bandung dalam upaya untuk menanggulangi permasalahan game DotA 2.

\section{B. Landasan Teori \\ DOTA 2}

DotA 2 adalah game online yang dimainkan secara tim yang dibagi menjadi dua tim dalam permainannya dengan lima orang disetiap tim nya. Didalam permainannya setiap pemain mengendalikan satu karakter / hero dimana tiap hero memiliki beberapa kriteria spesifik (Eggert, Herrlich, Smeddinck, \& Malaka, 2014) :

1. Kelebihan dan kekurangannya masing masing,

2. Kemampuan dan skill yang berbeda beda 
3. Mencocokan hero dengan barang atau item tertentu

4. Pemilihan dan mencocokan hero yang kita pilih dengan hero pemain lainnya.

Pemilihan karakter tertentu adalah aspek penting dari permainan. Tim membutuhkan keseimbangan karakter dengan kemampuan berbeda yang mampu memenuhi peran tertentu sehubungan dengan taktik dan strategi tim, menyerupai olahraga tradisional berbasis tim. Meskipun pengaturan inti tampak sederhana, ini dapat mengarah pada berbagai macam perilaku, peran, dan strategi berbasis tim yang kompleks. Para karakter mengembangkan kemampuan mereka dengan cara yang heterogen dan menjadi lebih kuat di sepanjang permainan dengan mengumpulkan poin pengalaman atau Experience dan emas atau gold (uang), yang dapat diinvestasikan para pemain ke dalam item-item yang mendukung kemampuan para karakter atau memberikan keuntungan lain ke tim. (Eggert et al., 2014).

\section{Traits}

Menurut Costa \& McCrae (2006) Trait didefinisikan sebagai dimensi-dimensi dari perbedaan individu dalam kecenderungannya memperlihatkan pola yang konsisten dari berpikir, merasa, dan bertindak. Setelah beberapa dekade, cabang psikologi kepribadian memperoleh suatu pendekatan taksonomi kepribadian yang dapat diterima secara umum yaitu dimensi "Big Five Personality".

\section{Big Five Personality Traits}

Dimensi Big Five pertama kali diperkenalkan oleh Goldberg pada tahun 1981. Dimensi ini tidak mencerminkan perspektif teoritis tertentu, tetapi merupakan hasil dari analisis bahasa alami manusia dalam menjelaskan dirinya sendiri dan orang lain. Taksonomi Big Five bukan bertujuan untuk mengganti sistem yang terdahulu, melainkan sebagai penyatu karena dapat memberikan penjelasan sistem kepribadian secara umum (John \& Srivastava, 1999).

Seiring perkembangan ilmunya, Strus, Cieciuch, \& Rowiński (2014) mengemukakan kelima dimensi Big Five sebagai Berikut :

1. Neuroticism (N) VS Emotional Stability (N), yaitu mengacu pada tingkatan reaktif dan stabilitas emosi, ketahanan emosi, dan toleransi terhadap emosi.

2. Extraversion (E), yaitu mengacu pada tingkatan aktifitas, energy, serta kemampuan bersosialisasi dan kepercayaan diri sosial (asertif).

3. Intellect (I) yaitu mengacu pada keterbukaan intelektual, kreatif, dan imajinasi.

4. Agreeableness (A) Agreeableness mengacu pada sikap positif dan negatif individu terhadap orang lain.

5. Conscientiousness (C), yaitu mengacu pada tingkat organisasi dalam ketekunan mengejar tujuan dan melakukan tugas tugas serta rentan terhadap ketertiban dan kepatuhan.

6.

\section{Hasil Penelitian dan Pembahasan}

Berikut adalah hassil penelitian mengenai Personality Traits Gamers Esports DotA 2 di kota Bandung dengan menggunakan alat ukur IPIP BFM-25 yang dimodifikasi oleh Akhtar \& Azwar, (2018) berdasarkan konsep Big Five Personality Traits oleh Strus, Cieciuch, \& Rowiński (2014) didapat hasil sebagai berikut : 


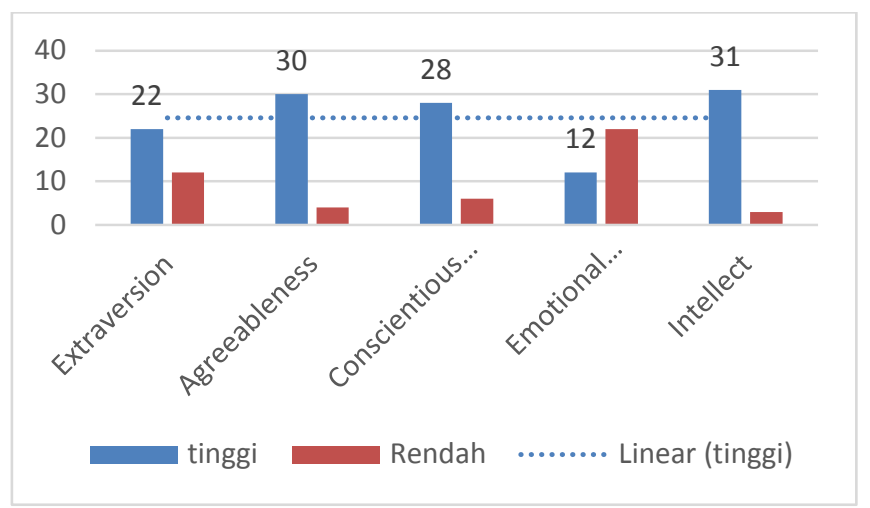

Gambar 1. Personality Traits Gamers Esports DotA 2 di kota Bandung

Dari hasil pengukuran pada tiap dimensi dari Big Five Personality traits pada gamers Esports yang aktif mengikuti kompetisi atau turnamen dalam 3 bulan terakhir. Pada dimensi Extraversion terdapat $12(35 \%)$ subjek dengan skor rendah dan $22(65 \%)$ subjek dengan skor tinggi. Pada dimensi Agreeableness terdapat 4 (12\%) subjek dengan skor rendah dan $30(88 \%)$ subjek dengan skor tinggi. Pada dimensi Conscientiousness terdapat $6(17 \%)$ subjek dengan skor rendah dan $28(83 \%)$ subjek dengan skor tinggi. Pada dimensi Emotional Stability terdapat $22(65 \%)$ subjek dengan skor rendah dan $12(35 \%)$ dengan skor tinggi. Pada dimensi Intellect terdapat 3 (9\%) subjek dengan skor rendah dan 31 (91\%) subjek dengan skor tinggi.

Dari hasil penelitian diatas diperoleh data bahwa terdapat 22 orang yang memiliki skor tinggi pada dimensi Extraversion, dimana hal tersebut menandakan sebanyak 65\% responden memiliki tampilan perilaku yang dimiliki gamers Esports DotA 2 memiliki persamaan dengan gamers secara umum, namun dimensi Extraversion tidak ditampilkan sebagai dimensi yang dominan pada skor tinggi, hal tersebut tentunya bertolak belakang dengan penelitian Teng (2008) yang menyebutkan bahwa gamers secara umum memiliki skor tinggi pada dimensi Extraversion, namun jika dikaitkan dengan fenomena yang peneliti angkat tentu hal ini baik, karena Extraversion berkaitan dengan orang yang menjadi kapten dari suatu tim. Tentu jika dalam suatu tim teridir dari 3 / 5 orang yang memiliki Extraversion tinggi, maka penyelesaiaan dan arah permainan akan terlalu banyak variasi yang dimana masing masing individu dengan skor tinggi akan bertahan pada pendapatnya, namun pernyataan tersebut harus dilihat individu tersebut apakah memiliki skor Agreeableness yang tinggi atau rendah, karena dimensi tersebut berkaitan dengan kemampuan seseorang untuk bekerja sama.

Pada dimensi Agreeableness terdapat 30 responden (88\%) dimana dimensi ini menjadi dimensi yang dominan pada skor tinggi yang dimiliki gamers Esports DotA 2, hal tersebut menunjukan bahwa meskipun dimensi ini tidak terkait dengan dua penelitian yang diangkat untuk menguatkan fenomena, namun berdasarkan pengertiannya dimensi Agreeableness kuat kaitannya dengan perilaku berkelompok, mengacu pada hasil Extraversion tentunya hal tersebut dapat menandakan meskipun dalam suatu tim memiliki skor tinggi pada dimensi Extraversion, para gamers disini dapat bekerja sama dengan baik antar sesama anggota timnya.

Hasil yang terdapat pada dimensi Emotional Stabillity menggambarkan bahwa dimensi ini menjadi dominan pada skor rendah. Sehubungan dengan penelitian Rachma \& Handoyo (2016) mengenai pekerjaan dapat dilihat dari hubungan antara data mengenai menjuarai suatu kompetisi dengan Emotional Stability. Dari hasil pengukuran terdapat data bahwa perbandingan pada responden yang memiliki skor rendah terdapat perbandingan $1: 2$ antara responden pernah menjuarai suatu kompetisi dengan yang belum pernah mejuarai suatu kompetisi, sedangkan pada responden yang memiliki skor tinggi terdapat perbandingan $1: 3$ pernah menjuarai suatu kompetisi dengan yang belum pernah mejuarai suatu kompetisi, hal tersebut menjelaskan bahwa memiliki emosi yang stabil tidak menjamin dia bisa menjuarai suatu kompetisi. Adanya responden yang memiliki skor tinggi namun tidak bisa menjuarai kompetisi dapat dipengaruhi oleh dimensi Agreeableness yang menekankan pada periaku kerja 
sama, Conscientiousness (disiplin dalam latihan) dan Intellect (kemampuan) yang menekankan pada keterampilan saat bermain.

Hasil dari dimensi Conscientiousness yang memiliki hasil dominan pada skor tinggi sebanyak 28 responden (83\%) bahwa kebanyakan gamers Esports DotA 2 memiliki kedisiplinan, dalam konteks bermain game seperti latihan, memiliki penyusunan strategi yang efisien, dan patuh jika mereka tidak menjadi kapten.

Hasil dari dimensi Intellect menjadi dimensi yang memiliki hasil paling dominan dengan skor tinggi sebanyak 31 responden $(91 \%)$ pada dimensi ini. Namun untuk menjelaskan mengapa ada yang memiliki skor rendah, faktor seringnya mereka latihan yaitu Conscientiousness dapat juga mempengaruhi.

\section{Kesimpulan}

Berdasarkan pembahasan dalam penelitian ini, peneliti menyimpulkan beberapa hasil penelitian sebagai berikut:

1. Secara keseluruhan, dimensi Agreeableness, Conscientiousness, dan Intellect adalah dimensi yang banyak memiliki skor tinggi dari 34 subjek, sedangkan dimensi yang paling banyak memiliki skor rendah adalah Emotional Stability dan dimensi Extraversion berada di tengah tengah. Kurangnya individu yang memiliki skor tinggi pada dimensi Extraversion dan banyaknya subjek yang memiliki skor tinggi pada Agreeableness memperlihatkan bahwa dalam gamers Esports di kota Bandung kurang memiliki individu yang bisa menjadi kapten didalam tim, hal tersebut dapat membuat kondisi permainan dalam komunikasinya menjadi pasif dan tidak terarah, serta kurangnya ide yang bisa diungkapkan ketika permainan berlangsung.

2. Dari dimensi Emotinal Stability yang paling banyak memiliki skor rendah terutama pada rank Divine hingga Immortal, dapat diambil kesimpulan bahwa memiliki skor tinggi pada dimensi Emotional Stability tidak terkait dengan menjadi gamers Esports, hal tersebut bertolak belakang dengan penelitian Rachma \& Handoyo, 2016 yang menyebutkan dimensi Conscientiousness, Emotional Stability, dan Openness / Intellect berpengaruh signifikan dalam konteks bekerja.

3. Kepopuleran game DotA 2 di Bandung disebabkan karena sebanyak 31 subjek (91,2\%) memiliki skor Intellect yang tinggi, dimana individu dengan skor Intellect yang tinggi menyukai hal yang kompleks dimana game DotA 2 memiliki banyak perpaduan kombinasi. Selain itu dimensi Agreeableness yang memiliki hasil dominan pada skor tinggi sebanyak 30 responden (88\%) menandakan bahwa kebanyakan para gamers Esports DotA 2 adalah orang yang ramah.

\section{E. Saran}

\section{Saran Teoritis}

Bagi peneliti yang tertarik mengambil penelitian yang serupa, sebaiknya penelitian dilakukan untuk menggambarkan gamers Esports di Indonesia, Selain itu karena game DotA 2 dimainkan secara kelompok perhatikan teori teori mengenai kelompok hubungannya dengan peran atau role yang ada di dalam game DotA 2.

\section{Saran Praktis}

Bagi orang orang yang ingin membuat organisasi Esports DotA 2 khususnya di Bandung, sebaiknya perhatikan komposisi di dalam timnya, setidaknya harus ada 1 individu dengan skor tinggi pada dimensi Extraversion.

\section{Daftar Pustaka}

[1] Akhtar, H., \& Azwar, S. (2018). Development And Validation Of A Short Scale For Measuring Big Five Personality Traits: The IPIP-BFM-25 Indonesia. Journal of Innovation in Psychology, Education and Didactics, 22(2), 167-174. Retrieved from http://www.jiped.ub.ro/wp-content/uploads/2018/11/JIPED_22_2_2018_3.pdf 
[2]. Collins, E., Freeman, J., \& Chamarro-Premuzic, T. (2012). Personality traits associated with problematic and non-problematic massively multiplayer online role playing game use. Personality and Individual Differences. https://doi.org/10.1016/j.paid.2011.09.015

[3]. Costa, P. T., \& McCrae, R. R. (2006). Age changes in personality and their origins: Comment on Roberts, Walton, and Viechtbauer (2006). Psychological Bulletin. https://doi.org/10.1037/0033-2909.132.1.26

[4]. Eggert, C., Herrlich, M., Smeddinck, J., \& Malaka, R. (2014). Entertainment Computing ICEC 2014. 8770, 112-125. https://doi.org/10.1007/978-3-662-45212-7

[5]. Rachma, D. A., \& Handoyo, S. (2016). Hubungan Antara Kepribadian Dengan Kemampuan Adaptasi Lintas Budaya Pada Expatriate Leader. Fakultas Psikologi Universitas Airlangga, (031), 1 of 13.

[6]. Strus, W., Cieciuch, J., \& Rowiński, T. (2014). The polish adaptation of the IPIP-BFM-50 questionnaire for measuring five personality traits in the lexical approach. Roczniki Psychologiczne, 17(2), 327-366.

[7]. Teng, C. I. (2008). Personality differences between online game players and nonplayers in a student sample. Cyberpsychology and Behavior, 11(2), 232-234. https://doi.org/10.1089/cpb.2007.0064 